\title{
Examining Task Oriented and Relations Oriented Team Diversity -An Analytic Review of the Banking Industry
}

\author{
Bushra Akbar Khan (Corresponding author) \\ Institute of Business Administration, Karachi \\ 76/11 8thStreet, off Khayaban-e-Badar, phase 6 \\ Karachi, Pakistan \\ Tel: +9-213-565-6776 E-mail: bushra.akhan@yahoo.com,bakhan@iba.edu.pk \\ Khadija Bari \\ Institute of Business Administration, Karachi \\ Main Campus, Karachi University \\ City Campus, Kayani Shaheed Rd., Karachi \\ E-mail:khaija_bari@hotmail.com
}

\author{
Received: April 18, 2011 \\ Accepted: September 15, 2011 \\ Published: November 21, 2011 \\ doi:10.5430/ijba.v2n4p3 \\ URL: http://dx.doi.org/10.5430/ ijba.v2n4p3
}

\begin{abstract}
In today's competitive business environment, organizations are compelled to stay on their toes at every second of their time to satisfy customers, solve economical and political problems, be cost efficient and innovative and establish a market value and name for itself. Tackling all these problems and hurdles and yet be innovative and creative cannot be managed by individuals alone. Hence, most organizations today have made use of teams, a group of people who work together towards a shared organizational goal. In teams, people from various backgrounds and expertise come together to give their opinion about a certain project so that all perspectives are kept in mind and collaborated before any decision is made. (O'Reilly et al., 1989). Since teams in organizations are made up of a diverse group of people hence there is always a possibility that they will not be able to work together. Banking Industry in Pakistan over the years has increased their focus on team work due to its challenging nature and ever changing demand for innovativeness and competitiveness. This study attempts to investigate the effects of task oriented and relation oriented diversity on team performance in the banking industry. Task oriented diversity involved factors like education, function and organizational tenure while Relation oriented diversity involved factors such as age, gender and ethnicity. The impact on team performance has been measured in terms of team members' opinion, team leader/DOH opinion and their satisfaction levels. The study has explored how task oriented and relation oriented diversity influences the team performance with respect to three contextual factors namely: Occupational Demography (majority dominated vs balanced), Industry Setting (service industry in particular banking industry) and Team Tenure (short term vs long term). The research findings revealed that the effects of relations - oriented and task oriented diversity on performance was significantly different with respect to contextual moderators and they offer new possibilities for enhancing team diversity outcomes. Therefore based on the study conclusions it is recommended that organizational practices especially HR policies and practices should consider the categorization and elaboration effects of task and relations oriented diversity in service industry. Similarly team tenure is also an important contextual moderator and diversity dynamics should be carefully understood for effective team outcomes especially in long term teams. Other industry level characteristics that have been ignored in earlier team diversity research should be examined since they offer new possibilities for enhancing team diversity outcomes.
\end{abstract}

Keywords: Relations Oriented Diversity, Task Oriented Diversity, Team Performance, Service Industry Settings 


\section{Introduction}

\subsection{Background of the Study}

In today's competitive business environment, organizations are constantly faced with setbacks and crisis to manage the widely changing and globalizing world. Organizations are compelled to stay on their toes at every second of their time to satisfy customers, solve economical and political problems, be cost efficient and innovative and establish a market value and name for itself.

Tackling all these problems and hurdles and yet be innovative and creative cannot be managed by individuals alone. Hence, most organizations today have made use of teams, a group of people who work together towards a shared organizational goal. These teams are usually made up of people from various departments to increase creativity and innovation. In teams, people from various backgrounds and expertise come together to give their opinion about a certain project so that all perspectives are kept in mind and collaborated before any decision is made. (O'Reilly et al., 1989).

Since teams in organizations are made up of a diverse group of people and there is always a possibility that they will not be able to work together. Diversity can be task oriented (e.g. tenure, function and education) and relations oriented (e.g. age, gender and ethnicity). The problem of diversity arises in almost every corporate team where different people from different backgrounds come together and work in coordination. Differences arise when people from different educational backgrounds and qualifications work together and there is often a difference in levels of understanding between people. A team usually has a common goal but everybody on that team might not have the same way of dealing with the situation and achieving that goal. This shows diversity in everybody's perspectives and attitudes - this variation in thought comes due to various kinds of diversity within a person or present in his external environment. (Milliken \& Martins, 1996).

Different cultural backgrounds also play a part. Since Pakistan has different cultural heritages from the different provinces, cultural diversity is bound to exist in corporate teams. Differences in gender and age may also contribute to possible problems. The differences, however, are not always conflictual. They might work in dynamics that are harmonious and work together to create synergy.

Banking Industry in Pakistan over the years has increased their focus on team work due to its challenging nature and ever changing demand for innovativeness and competitiveness. This report looks into how various banks in the private and foreign sector use teams to achieve their organization goals and distinguishes between the effects of task oriented and relation oriented aspects of diversity in relation to performance. This study will also examine how various aspects of diversity context can influence the categorization -based processes associated with relations-oriented diversity or the elaboration based diversity associated with task oriented diversity with implications for team performance (Van Knippenberg, De Duru, \& Homan, 2004).

\subsection{Problem Statement}

Most of the banks in Pakistan especially those belonging to private and foreign sector integrate most of their tasks and projects through work groups and teams. All these banks have a diversified employee base and the customer base whether corporate or consumer banking also comprises of a diversified demographic profile. Hence it was imperative to understand the importance of these diversity factors and their impact on team's performance.

\subsection{Research Objectives}

The study undertaken plans to investigate the following:

- To study the types of task oriented (e.g tenure, function and education) and relation oriented (e.g. age, gender and ethnicity) aspects of diversity in relation to team performance,

- To examine how various diversity factors affect the categorization based processes associated with relations oriented diversity,

- To examine how various diversity factors affect the elaboration based diversity associated with task oriented diversity,

- To examine the impact of relations and task oriented diversity on its performance with respect to contextual moderators like industry settings, occupational demography and team tenure.

\subsection{Significance}

In today's' cut throat competitive environment, large organizations such as the multinational companies are spending time in team building activities and giving much autonomous working environment as possible. Research findings from industrial and organizational psychology and other disciplines suggest several conditions necessary to manage diversity 
initiatives successfully and reap organizational benefits. This study reviews empirical research and theory on the relationship between team diversity and performance and outlines practical steps HR practitioners can take to manage diversity variables successfully and enhance the positive outcomes especially in banking industry where the organization come into direct contact with an equally diverse customer base.

\subsection{Limitations}

- Extracting information from the employees may prove to be a problem as the employees may be concerned about the various stigmas related to diversity issues like stereotyping etc and hence may have difficulty in disclosing the information.

- Limited sample size due to time limitation.

\subsection{Research Methodology}

The study undertaken involved both qualitative and quantitative research methods.

\subsubsection{Research Design}

The research design comprised of two stages. In the first stage a total of 8 in depth interviews ( 2 each from SCB, MCB, Citi Bank and Deutsche Bank) were conducted from employees who have been involved in supervising team work. The second stage consisted of a survey of 100 from the middle and lower management employees working in teams from various departments in these banks.

\subsubsection{Sampling Strategy and Sample Size}

Multi stage sampling was used as sampling strategy. In the first stage stratified sampling was used where the banking industry in Pakistan was divided into two main strata namely private sector and foreign banks. The second stage involved selection of two banks from each stratum through convenience sampling. This resulted in the selection of SCB and MCB in the private sector and Citi Bank and Deutsche Bank in the foreign banks sector. The sample for the eight in depth interviews was again based on convenience sampling selecting two team leaders/Department heads from each bank on the basis of their availability and willingness to participate in the study. The last stage required selection of the final sample of 25 respondents from each bank. A list of the employees belonging to both middle and lower management level working in teams under the team leaders/departments heads interviewed in the first stage was obtained .This list served as a sampling frame for the final sample selected through simple random sampling.

The target sample size for the questionnaires was 100 . However due to non response error the final sample analyzed for results came to be of 86 respondents. The response rate for the four banks was as follows:

$<$ Table 1 about here $>$

\subsection{Data Collection Method}

Primary data was collected through semi structured in depth interviews from the team leaders /department heads at two private sector banks and two foreign banks). Data collection also involved distribution of questionnaire among the employees at the head offices, Karachi of these private and foreign sector banks .Structured questionnaires were distributed among the respondents in the four banks. These questionnaires were divided into three parts. The first part involved questions regarding personal information such as age, education, organizational tenure department etc. The second part of the questionnaire investigated the type of diversity prevailing among the various teams to which the respondents belong and their opinion about the two categories of diversity namely relations oriented and task oriented. The third part of the questionnaire was designed to measure the impact of these diversity factors on team's performance in various contexts e.g. majority vs. balanced teams. Most of the questions were designed on Likert scale generating interval data for the hypothesis testing.

Secondary research involved a thorough analysis of related research articles and studies from both international and local journals.

\subsection{Data Analysis Method}

Qualitative analysis was used to interpret ate the data from interviews. Results and findings from the questionnaires were obtained by using descriptive statistics involving the use of percentages and mean score values. The mean score values were calculated on a scale of 1-5 where 1 was the most negative and 5 was the most positive. The proposed hypothesis were tested and concluded through $t$ tests using statistical software.

1.8.1 Statistical Test used

The hypotheses were tested using one tailed $\mathrm{t}$-tests. The $\mathrm{t}$ values were calculated from the frequency tables tabulated from the questionnaires using the following $\mathrm{t}$ formula 


$$
t=\frac{\bar{x}-\Delta}{\frac{s}{\sqrt{n}}}
$$

Where $x$ is the sample mean, $\Delta$ is a specified value to be tested, $s$ is the sample standard deviation, and $n$ is the size of the sample

These values were than tested at a significance level $(\alpha=0.05)$, degree of freedom $=n-1$ i.e 85 against $t$-values from the $t$ -distribution tables.

The formula for comparing the means of two populations using pooled variance is

$$
t=\frac{\bar{x}_{1}-\bar{x}_{2}-\Delta}{\sqrt{s_{p}^{2}\left(\frac{1}{n_{1}}+\frac{1}{n_{2}}\right)}}
$$

Where $x_{1}$ and $x_{2}$ are the means of the two samples, $\Delta$ is the hypothesized difference between the population means ( 0 if testing for equal means), $s_{\mathrm{p}}{ }^{2}$ is the pooled variance, and $n_{1}$ and $n_{2}$ are the sizes of the two samples. The number of degrees of freedom for the problem is

$$
d f=n_{1}+n_{2}-2
$$

If the two population distributions can be assumed to have the same variance deviation $-s_{1}$ and $s_{2}$ can be pooled together. The formula for the pooled estimator of $\sigma^{2}$ is

$$
S_{p}^{2}=\frac{\left(n_{1}-1\right) s_{1}^{2}+\left(n_{2}-1\right) s_{2}^{2}}{n_{1}+n_{2}-2}
$$

Where $s_{1}$ and $s_{2}$ are the standard deviations of the two samples and $n_{1}$ and $n_{2}$ are the sizes of the two samples.

\section{Literature Review}

Teams play a very significant role, not only because of their pervasiveness, but also due to the tasks they perform like problem solving, decision-making, and customer service (i.e highly interdependent tasks that require more than one individual). There is no doubt about the accomplishment of work by teams in today's corporate world and industry. (Cohen et al, 1996). Over the years workgroups and teams in most of the organizations have become increasingly diverse (demographically and functionally) and their success shows that this trend will continue in future years (Triandis et al., 1994; Williams \& O'Reilly, 1998). Various research studies have shown diversity to impact the performance and effectiveness of work-groups, but their analysis have indicated both positive and negative relation between diversity and performance ( Guzzo et al., 1996; Williams \& O'Reilly, 1998), Hence it has become crucial to investigate the underlying principles behind the team diversity-performance in organizational management theory and behavioral psychology.

In the late 1980's, normative models of team effectiveness (Hackman, 1987) were developed which investigated and recommended certain leverage points that practitioners can use to influence the team performance.

\subsection{Defining Teams}

Teams can differ from or taken as a special category of groups Teams are defined as two or more people with different tasks who work adaptively together to achieve specified shared goals (Hackman, 1987). Baker and Salas (1997) have defined a team as two or more individuals who have specific role assignments, perform specific tasks, and must interact and coordinate to achieve a common goal .In the present study, the term "team" is used to describe both work groups and teams if they meet the interdependency and other definitional requirements. 


\subsection{Defining Diversity}

Most of the management and psychological sciences literature has defined diversity as any attribute which may lead to the perception that another person is different from self (Triandis et al., 1994; Williams \& O'Reilly, 1998). Hence diversity can refer to a very large, arbitrary, number of dimensions, although majority of the researchers have generally concentrated on examining the effects of differences along readily visible dimensions such as gender, race, age, tenure, education, training, etc. (Milliken \& Martins, 1996)

\subsection{Social Category \& Functional Diversity Perspective}

Diversity, according to many researchers can be classified into two distinct groups: social category diversity, which consists of differences such as age, race, gender, etc., and informational/functional diversity which comprises of more job-related differences such as functional and educational background ( Jehn et al., 1999; Milliken \& Martins, 1996) .The social categorization perspective emphasizes on how similarities and differences within teams are used by group members to place each other into categories, with members generally preferring only to interact with other members perceived to be in their own category over members perceived to be in foreign categories (Turner et al., 1987). According to this school of thought when the work-group is extremely diverse, then the work-group will tend to divide into many sub-groups, and decreased interaction of these sub-groups may lead to an overall reduced performance for the workgroup. On the other hand, according to this perspective a relatively homogenous group will experience relatively greater levels of team member commitment (Riordan \& Shore, 1997; Tsui et al., 1992), greater group cohesion (O'Reilly, Caldwell \& Barnett, 1989), fewer relational conflicts (Jehn et al., 1999; Pelled, Eisenhardy \& Xin, 1999), so that one would expect homogenous groups to perform better than their heterogeneous counterparts (as evidenced in Jehn et al., 1999; Simons, Pelled \& Smith, 1999).

However if the diversity-performance relationship is investigated from the information/functional diversity perspective, the opposite conclusion (that heterogeneous groups should outperform homogeneous groups) is reached. Basically, the main idea here is that diverse groups should have a wider range of knowledge, and benefit from a larger number of contributing perspectives than homogeneous groups, and hence will be able to make better collective decisions and perform better and more creative work. This happens because as group members discuss their individual perspectives, conflict may occur where each group member argue over which viewpoint is better. Such conflict is considered to foster the environment for innovative solutions and creativity in general (Ancona \& Caldwell, 1992; Bantel \& Jackson, 1989; De Dreu et al., 2001)

\subsection{Task Related \& Relation Related Diversity Perspective}

Another perspective of understanding diversity similar to the social categorization, functional perspectives is classifying between the effects of task-oriented (e.g. tenure, function and education) and relations-oriented (e.g. age, gender, and ethnicity) aspects of diversity - performance link and investigating how various aspects of diversity context can influence the categorization-based processes associated with relations-oriented diversity or the elaboration-based processes associated with task-oriented diversity and their impact on team performance ( Van Knippenberg et al., 2004).

\subsection{Categorization- Elaboration Model}

There have been some very recent efforts to unify the various diversity-team performance perspectives. There are two fairly discrete viewpoints into a more modern view that acknowledges the coexistence of both informational/functional and social/categorical group responses to diversity, and specifically, that any given dimension of diversity is capable of both positively and negatively impacting performance (e.g. the CEM, Categorization-Elaboration Model) by van Knippenberg et al., 2004).

\subsection{Team Design and Team Performance}

Realizing the importance of team effectiveness, most of the recent team research has focused on variables related to the effectiveness and performance of teams .Early research work such as McGrath's (1964) input-process-output model focused on group dynamics. However, Hackman(1987) introduced his normative model of team effectiveness which brought a major paradigm shift in team research. Most of Hackman's work summarized and extended knowledge about the team design and recommended guidelines for effective structure and management of teams in organizations. His approach brought a major shift away from models that only focused on group dynamics (e.g. McGrath's input-process-output model, 1964) and instead integrated on information that could be used in making teams more effective.

According to Hackman's normative model, team effectiveness is a joint function of three "process criteria of effectiveness": (a) the amount of knowledge and skill team members can contribute to the team task, (b) the level of 
effort the members expend on the team task, and (c) the appropriateness of performance strategies to the task that are used by team members. Similar to Hackman, later researchers (e.g. Campion et al., 1993; Campion et al., 1996; Guzzo et al., 1996) have echoed team design, context, and process as points of leverage through which researchers and practitioners can influence team performance and hence effectiveness.

The relationship between team design variables and team effectiveness may be of particular interest to both researchers and managers. Specifically, the design of the team sets the boundaries within which the team must function.

Given the potential importance of team design and composition as a point of leverage in enhancing team effectiveness, the present study focuses on the relationships between team composition variables (like relation oriented and task oriented diversity variables) and team performance, both from the perspective of the group members and the team leaders and department heads and team satisfaction

\subsection{Demographic Diversity}

Wiersema and Bantel (1992), in their study suggested that an individual's demographic background is a determinant of his or her cognitive base. When members of a group differ with respect to variables like gender and functional background, they may have different interests, values, and mental scripts-i.e., expected sequences of actions or events (Ancona, 1990).

Demographic diversity has traditionally been identified into two main classifications. One approach has been to make statements about heterogeneity or homogeneity in general, rather than about a particular type (e.g. age diversity) (Hambrick et al., 1984).The second approach has been to treat each demo- graphic diversity variable as a distinct theoretical construct based on the argument that different types of diversity may produce different outcomes. For example, Hoffman and Maier (1961) studied that "mixed-sex groups tended to produce higher quality solutions than did all-male groups". Hence these researchers built their theory and conclusions focused on a particular type of demographic diversity. Zenger and Lawrence (1989) gave more dimensions to this approach analyzing several types of diversity (age and organizational tenure) in their field study of demography and communication frequency. Both approaches have been accepted and widely used. This paper has used a middle-ground approach, following Zenger and Lawrence and therefore focuses on relation oriented (age, gender, ethnic) and task oriented (tenure, function, education) diversity in organizational context.

\subsection{Industry Setting and Team Diversity}

Industry settings may have important implications for diversity dynamics in more specific business environments in which teams may be nested. The literature review of various management and organizational practices show that in past diversity research had a limited focus on Industry-level context (e.g. Ancona \& Caldwell, 1992; Lovelace et al., 2001; Reagans et al., 2001). Many Research studies have indicated that since service-oriented industries are involved more frequent and closer interactions with customers, enhancing diversity based on demographic attributes in such industries can actually enhance a firm's "market competence" giving it a competitive advantage in the service industry (Richard et al., 2007). Hence in the service industry, it is expected that greater gender, race or age diversity is likely to have positive rather than negative performance outcomes (Joshi et al., 2009) However, the manufacturing industry is often characterized by a greater reliance on physical capital/equipment and relatively less frequent direct customer-based interactions (Quinn et al., 1996), hence diversity attributes are less likely to directly impact performance in this industry setting (Richard et al., 2007). As compared to these service and manufacturing industries, high-tech industries depend more on intellectual capital and invest relatively more in research and development (OECD, 2006).Thus, based on these views, it can be assumed that task-oriented attributes that can enhance a team's cognitive resource base may have a more significant direct impact on performance outcomes in high tech industries. Based on the theoretical and empirical perspective detailed above, this study proposes that

Hypothesis 1: Relations Oriented Diversity is likely to have a positive effect on performance in service oriented industries

\subsection{Occupational Demography}

Many studies from sociological research indicates that occupation level demographics have important implications for gender, ethnicity or age based diversity in organizations (Reskin et al., 1999). A significant part of social research on stereotype formation has specified the psychological processes by which the occupational demography in organizations can influence diversity dynamics within teams Occupational demography (majority-dominated versus balanced) serves as the situational setting that can enhance the effects of relations-oriented diversity and minimize the effects of task-oriented diversity on team performance(Joshi et al.,2009) 
According to (Brewer, 1988), once categorization-based processes are evolved, additional information about targeted group members is filtered out and individuating processes are completely blocked .These categorization-based processes are likely to influence interactions in diverse teams especially when the environment evokes negative stereotypes against certain particular demographic groups, In a recent study, Lepine et al. (2002) questioned the relationship between sex and team performance and found that all-male teams (majority dominant vs. balanced) were the worst configuration for performance on a decision-making task (even though it was a masculine-type task). Male teams tended to make decisions that were overly aggressive. Thus, given the change in women's interactions and roles in organizations, the specific effects of sex on team effectiveness (or for that matter, which demographic variables will be task work-related) are relatively unclear

Another study analyzing occupational age, also suggested that negative stereotypes against older workers are fairly common and can have negative implications for these workers (Fiske et al., 2002). This study suggests that older workers may face more unfavorable outcomes in occupations composed of relatively fewer older workers i.e. majority dominant younger workers. Integrating these viewpoints this research, propose that majority-dominated occupational settings (i.e. male, whites, or younger-worker dominated occupations) are likely to evoke stereotypic reactions against minority groups (Fiske, 1993; Reskin et al., 1999). The integration of these reactions results in categorization-based processes that hinder effective group interactions and hence result in detrimental performance consequences (Larkey, 1996). Therefore, this study test the following proposition

Hypothesis 2a: Relation oriented diversity will have a negative impact on team performance in majority dominant teams.

Hypothesis $2 \boldsymbol{b}$ : Relation oriented diversity will have a positive impact on team performance in balanced teams

Hypothesis 2c: Team diversity will have a significantly more positive impact on team performance in balanced teams than in majority teams

\subsection{Time and Team Tenure}

Another important variable of the diversity-team performance link is the temporal dynamics of the team. Usually teams have a history and a future (Brannick et al., 1997) both of which influence current behavior (Hackman, 1992; McGrath, 1990 \& 1991). Hence team tenure is an important factor because the length of time teams have worked together can have a significant effect on team processes and thus may affect the team diversity/team performance relationships. (Joshi et al., 2009)The tenure and durability of a team, that is, whether the team has been grouped to achieve a goal in the short-term or long term and whether it is a permanent unit in an organization is likely to major implications for interpersonal interactions among diverse team members. In a recent study, Schippers and colleagues (2003) found that in the long run, more diverse teams were less likely to display elaboration-based processes. Over short-run, diverse teams however had greater task-relevant debates and discussions resulting in positive influence on team performance. The same study also noted that in more tenured diverse teams, team members had more conflicts due to relational differences and the motivation to resolve differences through interaction and communication phased out over the time. On the other hand, in the short term, most of the team members in highly diverse teams communicated their differences to accomplish the team's task (Schippers et al., 2003; Watson et al., 1998). Based on this view, the present study test the following proposition

Hypothesis 3a: The impact of relations oriented diversity will be significantly positive in short term teams

Hypothesis 3b: The impact of relations oriented diversity will be significantly negative in short term teams

Hypothesis 3c: The impact of task oriented diversity will be significantly more positive in short term teams than in long term teams

\section{Data Analysis and Key Findings}

Primary data collection involved semi structured interviews and structured questionnaires from the respondents. The questions were asked to analyze the effects of task oriented and relation oriented diversity on team performance. Task oriented diversity involved factors like education, function and organizational tenure while Relation oriented diversity involved factors such as age, gender and ethnicity. The impact on team performance has been measured in terms of team member's opinion, team leader/DOH opinion and their satisfaction levels. The study sets out to find how task oriented and relation oriented diversity influences the team performance with respect to three contextual factors namely: Occupational Demography (majority dominated vs balanced), Industry Setting (service industry in particular banking industry) and Team Tenure (short term vs long term). 


\subsection{Interview Data Findings}

Semi structured interviews were carried out in all the four banks. The target respondents were one team leader and one team supervisor or department head from each bank. An analysis of the interview responses showed that most of the team leaders were mainly those who had the longest organizational tenure among the team member while in some cases it was the oldest member or the most skilled (technical knowledge) who was selected as the team leader. The team leaders' task included coordinating and mentoring their team providing them with strategic direction to achieve their team objectives. Accept for MCB all other teams normally constituted of 2-5 members whereas at MCB the current team practice was both small teams 2-5 people and also as large as 50-100 members in case of major projects specially in IT department. Different questions were asked from these respondents to identify the various diversity factors and their influence on team's performance. The satisfaction level of both the team leaders and Department heads was gauged through the interviews in order to determine the teams' overall performance and effectiveness.

\subsubsection{Team Diversity}

All the teams were diverse with respect to age, gender, ethnicity, organizational tenure, educational back ground, religion, position in the organization and function. Although teams were not intentionally formed in favour of any particular diversity variable but they were still very much demographically diverse in their composition because of an overall diverse employee base in the banking industry.

\subsubsection{Diversity Factors and Their Effects}

Age, education and function were the main elements of diversity in the banking industry. Other diversity factors included organizational tenure, position in the organization, gender, ethnicity and religion.

\subsubsection{Age Diversity}

Almost all the team leaders and department heads believed that age diversity brings more cohesiveness in teams and create an environment of building relationships, sharing experiences from the older ones and more enthusiasm an efficiency from the younger team members.

\subsubsection{Gender Diversity}

Gender diversity prevailed in the banking industry and according to the interviewees no discrimination was made against any specific gender. However since the overall percentage of working women is lower than males in Pakistan the same is witnessed in the banking industry also. All the respondents believed some times while selecting team's male employees are preferred over females in the organizations for particularly difficult tasks such as field visits etc.

\subsubsection{Ethnic Diversity}

In Pakistan's banking industry ethnic diversity had a positive effect on the team performance compared to the diverse workplace cultures in USA and Britain. Most of the employees working were Pakistani but ethnically different that was Pathans, Sindhis and Punjabis. The ethnic diversity had a positive role in case of teams involved in customer service since different ethnic customer base existed in all these banks and ethnical diversity helped in dealing and creating relationships. The presence of a good mix of provincial representation in the teams contributes somewhat positively to the team performance.

\subsubsection{Education and Functional Diversity}

Another important element of diversity included diversity with respect to qualification and skills. Each team member was professional in a respective field and every department was being lead by an expert. These qualified people, which Included BBA's, MBA's, CFA's and engineer cum MBA's can play role of team leaders as well as team members. Functional diversity was also a common factor in all the banks with team members belonging to different functions such as OCC, CRU, Corporate Banking, Treasury, and IT etc. The good mix of skill diversity contributed positively to the working of the team by making it more efficient in every way as work was more effectively divided between the people whose skills and qualifications were the most suitable to it.

\subsubsection{Organizational Tenure}

Organizational tenure was also an important demographic variable for creating diverse teams .Higher diversity with respect to tenure was attributed to have a positive influence where those who had been in the organization for longer duration helping and sharing their experiences with new comers. 


\subsubsection{Majority Dominant versus Balanced Teams and Their Impact on Teams Performance}

\subsection{8.i Relations Oriented Diversity:}

Majority dominated occupational settings i.e. males, younger- worker dominated occupations can result in stereotyping reactions and may hinder effective group interactions. The interview data revealed that in majority dominant teams the influence of age, gender or ethnic majority groups resulted in negative performance consequences and hence all the team leaders and department heads intentionally avoided such team compositions. They preferred to select team members such that they could not make groups and categorize on the basis of age, gender or ethnic majority. They all believed that the positive impact of relation oriented diversity in the service industry was only witnessed in balanced teams.

\subsection{8.ii Task Oriented Diversity}

According to literature review task related diversity had a lesser positive impact on team performance in majority dominant teams due to categorization process however the analysis of the interview data showed that almost all those team leaders and HOD interviewed believed that education, functional background and organizational tenure majority in a team had a positive influence on its performance. This was attributed to the reason that teams were assigned for particular tasks e.g. IT issues or Consumer service, and hence having more people with similar required qualification had a positive impact on teams' performance .These group of people with specialized education/function or experience were able to deliver more positive effects than working in balanced teams.

\subsubsection{Short Term Versus Long Term Teams}

\subsection{9.i Relations Oriented Diversity}

Majority of the respondents interviewed believed that the conflicts which normally arise due to age, gender or ethnical diversity were witnessed more in long term teams since the motivation to solve these relational issues phased out over time. As compared to long term teams the relationally diverse team members working in short term tenured teams communicated their differences to accomplish the task due to time constraints and hence had positive performance outcomes.

\subsection{9.ii Task Oriented Diversity}

When interrogated about the influence of task diversity factors in short term teams majority of the respondents believed that the impact was more positive in short term than in long term. This was believed to be due to the fact that over the long run elaboration based processes slowed down. The interviewees were of the opinion that short term teams had greater task related debates resulting in constructive solutions. This belief was in accordance with the proposed hypothesis $3 \mathrm{c}$ for the current study (section 2.10)

\subsubsection{Satisfaction with diverse team performance}

An overwhelming majority of the respondents comprising of team leaders and HODs believed that diversity helps to understand people in a better way and even employees from different branches coordinate with each other and get to know about each others' culture and the external environment. Hence they all agreed that demographic diversity played a crucial role in teams success. This belief was also backed by the outcome evaluation of the teams' performance as quoted by the team leaders and respective HOD.

\subsection{Questionnaire Data}

The four banks under consideration are SCB and MCB from the private sector and Citi Bank and Deutsche Bank from the foreign sector. The Questionnaires were distributed to 25 employees from each of the four banks .The overall response rate was $86 \%$, (SCB: 96\%, MCB: $80 \%$, Citi Bnak: $80 \%$ and Deutsche Bank: 88\%). Hence a final sample of 86 employees was attained.

\subsubsection{Demographic Characteristics of the respondents_}

Majority of the employees (48\%) in the sample, fall in the age bracket of 25-30 years and were males(78\%).They belonged to various functional background with most of them employed in the IT department (39\%), followed by corporate banking department (27\%). The respondents mostly comprised of lower management(76\%) and had various ethnic backgrounds ( Punjabi 48\%, Urdu speaking 38\%,Sindhi $6 \%$ and Pathan $13 \%$ ). The organizational tenure varied from 0 to more than 5 years with majority $(79 \%)$ been in the organization for 2-4 years. The educational background varied from being MBA 58\%), CFA (21\%) and BBA (12\%). 


\subsubsection{Practice of Teamwork}

One of the objectives of the research project was to analyze the practice of teamwork in the banking industry of Pakistan. The analysis of the questionnaires showed that $100 \%$ of those interviewed had been involved in teamwork as a part of their employment with the bank. As is evident from the table below, working in teams is becoming a widespread phenomenon in banks today, both foreign and local.

The employees interviewed worked as part of the team majority of the time as is evident from the response below. $97 \%$ of the employees interviewed were currently involved in an activity or project that involved working as a part of the team while only $3 \%$ were working alone. This shows that there is a trend toward more group assignments rather than individual assignments in the banking sector.

\subsubsection{Type of Diversity}

The employees at all the four banks who were currently working in teams were interacting with other employees who belonged to various diverse backgrounds, ethnicity, educational backgrounds, genders, designations, organizational function etc. The most prevalent diversity factors were age $(80 \%)$, function $(77 \%)$ followed by educational background $(73 \%)$ and organizational tenure $(62 \%)$.

\section{$<$ Table 2 about here $>$}

\subsubsection{Effects of Relations Oriented Team Diversity in Service Industry}

The questionnaire that was distributed among employees at the four banks also aimed at analyzing the effects of team diversity on performance. This effect was measured on a numerical scale of $1-5$, where 5 meant very positive and 1 meant very negative. For analysis of questions, mean scores were used to find out which of the diversity factors had a major effect on team performance. The average rating on the scale used was 3 which meant a neutral response whereas score below 3 meant negative impact and above 3 meant a positive impact.

For relations oriented diversity, there was not much difference in the impact of the various relation oriented factors. Gender had the highest mean score of 3.3 showing a relatively above average positive impact on team performance as compared to age and ethnicity which had a mean score of 3.1 each. This showed that overall relational diversity had positive effects in service industry.

\section{<Table 3about here $>$}

Testing Hypothesis 1:

Ho: Relations oriented diversity is likely to have neither a positive nor a negative impact on team performance in the service industry

Ha: Relations oriented diversity is likely to have a positive impact on team performance in the service industry

So Ho: $\mu=3$

Ha: $\mu<3$

The hypothesis were tested using one tailed $\mathrm{t}$-tests using the following $\mathrm{t}$ formula

$$
\begin{aligned}
t & =\frac{\bar{x}-\Delta}{\frac{s}{\sqrt{n}}} \\
& =2.67
\end{aligned}
$$

Where, $\Delta=\mu=3$ since 3 is an average neutral value on a scale of $1-5, s=0.62, x=3.16, n=86($ table 3.1$), \alpha=0.05$

Critical Region: $t$ calculated $>$ t0.05, 85

Conclusion: since the calculated value of $\mathrm{t}$ falls in the critical region hence Ho may be rejected and it may be concluded that relation oriented diversity will have a significantly positive impact in service industries.

\subsubsection{Effects of Task Oriented Team Diversity in Service Industry}

In the category of task oriented diversity, differing educational backgrounds had the most positive impact on team performance as indicated by a mean score of 3.2, as compared to that of a different functional department (3.0) and organizational tenure (3.1).

$<$ Table 4 about here $>$ 


\subsubsection{Impact of Relations Diversity in Majority Dominant Teams:}

Majority dominant teams are those teams that have a majority of team members with similar backgrounds in terms of diversity factors of age, gender, ethnic, functional, educational and organizational tenure.It was believed that in such teams, emloyees with similar factors in majority may make groups against those in minority. Means score values were used to asses the impact in the analysis.

The results showed that in the category of relations oriented diversity, the highest score was that of age (2.4). Even this was a below average rating on a scale of 5 . It was followed by gender and ethnic diversity (1.9 each). Thus, in case of majority dominant teams, relations oriented diversity factors had a negative effect on team performance.

$<$ Table 5 about here $>$

Hypothesis 2a:

Ho: Relations Diversity will have not have any negative or positive impact on team performance in majority dominant teams

Ha: Relations Diversity will have a negative impact on team performance in majority dominant teams

The hypothesis were tested using one tailed t-test

where, $\mathrm{t}$ calculated $=-11.9 \Delta=\mu=3$ since 3 is an average neutral value on a scale of $1-5, s=0.78, x=2.06, n$ $=86($ Table 5), $\alpha=0.05$

Conclusion: since the calculated value of $t$ falls in the critical region hence Ho may be rejected and it may be concluded that relation oriented diversity will have a negative impact in majority dominant teams

\subsubsection{Impact of Task Oriented Diversity in Majority Dominant Teams}

In case of task oriented diversity, all three diversity factors received the same weighted average score of 3.2, i.e., function the employee belongs to, his/her educational background, and organizational tenure, all have a positive impact in increasing team performance in majority dominant teams.

\section{$<$ Table 6 about here $>$}

\subsubsection{Impact of Relations Diversity in Balanced Team}

The study also investigated the diversity factors, both relations oriented diversity and task oriented diversity, in terms of their effect on team performance in a balanced team. A balanced team is one in which there is no majority dominant group with respect to the diversity factors adressed in this report.

The reponses were analysed using mean score values. The highest scores were attained by gender and ethnic diversity( 3.8 each). This relatively high above average scores of 3.8 on a scale of 5 showed that in case of a balanced team, having people of both genders and those belonging to different ethnic backgrounds positively affected team performance. However, a lower score was attained by the age factor(3) but it showed that even age diversity had a positive effect on team performance in a balanced team.

Hypothesis $2 b$ :

Ho: Relations Diversity will not have any negative or positive impact on team performance in balanced

Ha: Relations Diversity will have a positive impact on team performance in majority dominant teams

The hypothesis were tested using one tailed $\mathrm{t}$-tests where, $\mathrm{t}$ calculated $=8.05, \Delta=\mu=3$ since 3 is an average neutral value on a scale of $1-5, s=0.61, x=3.53, n=86$ (Table 7), $\alpha=0.05$

$<$ Table 7 about here $>$

Conclusion: since the calculated value of $t$ falls in the critical region hence Ho may be rejected and it may be concluded that relation oriented diversity will have a positive impact in balanced teams

\subsubsection{Impact of Task Oriented Diversity in Balanced Teams}

The assessment of task oriented diversity effects in balanced teams showed that all three diversity factors received the same weighted average score of 3.2, i.e., function that the employee belongs to, his/her educational background, and organizational tenure, all have a positive impact in increasing team performance in balanced teams.

$<$ Table 8 about here $>$ 


\section{Hypothesis 2c:}

Ho: Task oriented diversity in balanced teams is likely to have no significant difference in its impact on team performance than in majority teams

Ha: Task Oriented Diversity in balanced teams is likely to have a significantly more impact on team performance than in majority teams.

$$
\begin{aligned}
& \text { Ho: } \mu 1-\mu 2=0 \\
& \text { На: } \mu 1 \quad \mu 2
\end{aligned}
$$

.T-test

$$
t=\frac{\bar{x}_{1}-\bar{x}_{2}-\Delta}{\sqrt{s_{p}^{2}\left(\frac{1}{n_{1}}+\frac{1}{n_{2}}\right)}}
$$

Where $\Delta=0, s_{\mathrm{p}}{ }^{2=0.417}, \mathrm{x} 1=3.2, \mathrm{~s} 1=0.643$ (Table 8), $\mathrm{s} 2=3.2, s 2=0.649$ (Table 6), $d f=170, \alpha=0.05$

Conclusion: since calculated $t$ does not fall in the critical region hence we cannot reject Ho and conclude that there is no significant difference between effects of task oriented diversity in majority and balanced teams

\subsubsection{Relations Diversity and Short Term Teams}

The report was aimed at analyzing the effect of diversity factors on the teams performance when people work as a team for a short term .A short term team for this study was defined as a team which worked for less than 3 months or members were rotated after every 3 months. In the category of relations oriented diversity, the highest scores were attained by gender and ethnic diversity $(3.3$ each). This mean score values indicated that in case of working with a team for a short term, having people of both genders and those belonging to different ethnic backgrounds positively affected team performance. Thus it showed that in short term relations diversity had a positive impact which also supported the hypothesis 3 a proposed in this study.

$$
<\text { Table } 9 \text { about here }>
$$

Hypothesis 3a:

Ho: Relations Diversity will not have any negative or positive impact on team performance in short term teams

Ha: Relations Diversity will have a positive impact on team performance in short term teams

The hypothesis were tested using one tailed $\mathrm{t}$-tests using the $\mathrm{t}$ formula where, $\mathrm{t}$ calculated $=3.43, \Delta=\mu=3$ since 3 is an average neutral value on a scale of $1-5, \mathrm{~s}=0.62, \mathrm{x}=3.23$ (Table 9), $\mathrm{n}=86$ (table), $\alpha=0.05$

Conclusion: since the calculated value of $\mathrm{t}$ falls in the critical region hence Ho may be rejected and it may be concluded that relation oriented diversity will have a positive impact in short term teams

\subsubsection{Task Oriented Diversity and Short term teams}

The assessment of task oriented diversity in short term teams indicated that the diversity factors of function and education received the same slightly above average mean score values of 3.2 followed by organizational tenure with a mean score of 3.0.Thus overall task diversity had neither a very positive nor a very negative impact on teams when working in short term or temporary teams.

\section{$<$ Table 10 about here $>$}

\subsubsection{Relations Oriented Diversity and Long Term Teams:}

Long Term teams are those teams whose team members are mostly permanent and work together for a longer period.For this study long term was taken as working together for more than 3 months. The study analyzed the effects of relations diversity factors on long term teams performance. The meam scores attained by age, gender and ethnic diversity (2.7,2.5 and 2.7respectively ) showed that in contrast to short term teams, none of these factors had any positive contribution in long term. This belief was also supported by the hypothesis $3 \mathrm{~b}$ proposed in this study.

$<$ Table 11 about here $>$ 


\section{Hypothesis 3b:}

Ho: Relations Diversity will not have any negative or positive impact on team performance in long term teams

Ha: Relations Diversity will have a negative impact on team performance in long term teams

So Ho: $\mu=0$

Ha: $\mu<3$

The hypothesis were tested using one tailed $\mathrm{t}$-tests, where $\mathrm{t}$ calculated $=-5.28$

$\Delta=\mu=3$ since 3 is an average neutral value on a scale of $1-5, s=0.71, x=2.63, n=86($ table $), \alpha=0.05$

Conclusion: since the calculated value of $\mathrm{t}$ falls in the critical region hence Ho may be rejected and it may be concluded that relation oriented diversity will have a negative impact in long term teams

\subsubsection{Task Oriented Diversity and Long Term Teams}

The assessment of task oriented diversity in the context of long term teams showed that the diversity factors of education obtained a slightly above average mean score of 3.3, i.e., having people with varied educational backgrounds has a positive impact in increasing team performance in working for teams for a long term. This wa s followed by Function and Organizational tenure ( $3.1 \mathrm{each}$ ). The results showed almost a similar effect for both short term and long term teams showing that team tenure did not have significant impact in context of task oriented variables.Hence the results did not support the hypothesis $3 \mathrm{c}$ proposed in this study

$<$ Table 12 about here $>$

\section{Hypothesis 3c:}

Ho: Task oriented diversity in short term teams is likely to have no significant difference in its impact on team performance than in long term teams

Ha: Task Oriented Diversity in short term teams is likely to have a significantly more impact on team performance than in long term teams.

$$
\begin{aligned}
& \text { Ho: } \mu 1-\mu 2=0 \\
& \text { На: } \mu 1 \quad \mu 2
\end{aligned}
$$

.T-test

$$
t=\frac{\bar{x}_{1}-\bar{x}_{2}-\Delta}{\sqrt{s_{p}^{2}\left(\frac{1}{n_{1}}+\frac{1}{n_{2}}\right)}}
$$

Where $\Delta=0, s_{\mathrm{p}}{ }^{2=0.21}, x 1=3.12$ and $x 2=3.16$ (table ), $d f=170, \alpha=0.05$

Conclusion: since calculated $t$ does not fall in the critical region hence we cannot reject Ho and conclude that there is no significant difference between effects of task oriented diversity in short and long term teams

3.2.14 Satisfaction while Working in Teams:

When working in teams, there are people from varied backgrounds and working together as a cohesive group is the key to superior team performance. If an employee is not satisfied when working in a team especially in the banking sector, then working with the organization may become an everyday challenge. Majority of the respondents were satisfied with their teams' performance as shown by a high above average mean score value of 3.86 .

3.2.15 Future Likelihood of Working in a Team:

Employees were asked to rate their likelihood of working in diverse teams in the future and their inclination towards working for such a team. Majority of the people were willing to work in a team in the future also as indicated by an above average mean score of 4 on a scale of 5 . 


\section{Conclusion}

The research findings revealed that while diversity does matter for team performance, it matters more in certain contexts. It was also observed that the effects of relations -oriented and task oriented diversity on performance were significantly different with respect to contextual moderators.

An important implications of this study findings showed that in service industry context diversity can have positive effects. This is mainly due to the market competence perspective (Richard et al., 2007) and increased level of customer interaction (Joshi et al., 2009). The study results revealed that relations diversity had a positive impact on performance (mean score values : combined mean $=3.16$, age $=3.1$, gender $=3.3$, ethnic $=3.1$ ) in service industry. Hence the results supported our first hypothesis as was also observed from the literature (Joshi et al., 2009) and interview findings.

It was also indicated that in majority dominant occupational settings ,relations oriented diversity had negative impact on performance out comes (mean score values :combined mean $=2.06$, age $=2.4$, gender $=1.9$, ethnic $=1.9$ ). The results supported the proposed hypothesis $2 \mathrm{a}$ and the earlier research also suggested the same hindering effects in majority dominant teams(Larkey,1996).As predicted in the hypothesis $2 b$, the study findings also revealed that these negative effects of categorization processes in majority dominant teams became positive when teams were balanced (mean score values: combined mean $=3.53$, age $=3$, gender $=3.8$, ethnic $=3.8$ ). These results were also in agreement with the interview findings. However the proposed hypothesis $2 \mathrm{c}$ was partially supported, as interview results were in agreement but survey findings concluded that there was no significant difference in the effects of task related diversity in balanced settings as compared to majority dominant settings. Therefore the positive impact of task oriented diversity remained almost same for both types of occupational settings.

Another key implication of this study was the impacts of relation oriented diversity in short and long term teams. The findings revealed that that the impact on team performance in short term teams was positive(mean score values : combined mean $=3.23$, age $=3.1$, gender $=3.3$, ethnic $=3.3$ ). This was in accordance with the study proposition $3 \mathrm{a}$ which was also supported by the interview results .In the long run, however divisions based on relations oriented diversity may become more debilitating for the team performance (Schippers et al., 2003).As predicted the long term impact of relation diversity factors was negative(mean score values : combined mean $=2.63$, age $=2.7$, gender $=2.5$, ethnic=2.7) . This along with the interview results supported the hypothesis $3 \mathrm{~b}$ proposed in this study.

In the short run, diverse teams engaged in greater task relevant debates that had positive consequences for team performances (Schippers et al., 2003; Watson, Johnson \& Merrit, 1998). The study findings revealed that the effect of task diversity were positive in the short term (mean scores combined mean $=3.12$, function $=3.2$, education $=3.2$,org.tenure $=2.98$ ) and long term (mean scores: combined mean $=3.16$, function $=3.1$,education $=3.3$, org.tenure $=3.1$. . Hence there was not any significant difference in the impact of task diversity in the short run as compared to long run. Therefore the proposed hypothesis $3 \mathrm{c}$ did not find any support from this studys' findings. It can be concluded that a contextualized analysis of team diversity dynamics carried out in the present study provides some important insights into team diversity dynamics in general and for relations oriented diversity in particular.

\section{Recommendations}

The present study revealed that although diversity is important for team dynamics, it matters more in some contexts like occupational demography, industry settings and team tenure. Therefore based on the study conclusions it is recommended that:

Organizational practices especially HR policies and practices that favour some demographic groups over others should consider the categorization and elaboration effects of task and relations oriented diversity in service industry .This would be helpful in introducing work group practices with minimum inequities and differences among the group members.

Service oriented industries require direct customer contact so that the costs of negative categorization-based interactions also become high. Therefore, such firms should involve in proactive diversity management practices that consider age, gender or ethnic issues at the work place resulting in positive implications for performance. For instance special training sessions intended at changing attitudes aimed at demographically dissimilar team members as well as customers may be introduced in such settings.

Similarly team tenure is also an important contextual moderator and diversity dynamics should be carefully understood for effective team outcomes especially in long term teams. Other industry level characteristics that have been ignored in earlier team diversity research should be examined since they offer new possibilities for enhancing team diversity outcomes. 


\section{References}

Ancona, D. G. (1990). Outward Bound: Strategies for Team Sur-vival in an Organization. Academy of Management Journal, 33, 334-365. http://dx.doi.org/10.2307/256328

Ancona, D. G., \& Caldwell, D. F. (1992). Demography and design: predictors of new product team performance. Organization Science, 3, 321-341. http://dx.doi.org/10.1287/orsc.3.3.321

Baker, D. P., \& Salas, E. (1997). Principles and measuring teamwork: A summary and look toward the future. In M. T. Brannick, E. Salas, \& C. Prince (Eds.), Team performance assessment and measurement: Theory, methods, and applications, 331-355.

Bantel, K., \& Jackson, S. (1989). Top management and innovations in banking: does the composition of the team make a difference? Strategic Management Journal, 10, 107-124. http://dx.doi.org/10.1002/smj.4250100709

Brannick, M. T., \& Prince, C. (1997). An overview of team performance measurement. In M. T. Brannick, E. Salas, \& C. Prince (Eds.), Team performance and assessment and measurement: Theory, methods, and applications,. 3-18.

Brewer, M. B. (1988). A dual-process model of impression formation.n T. K. Srull \& R. S. Wyer (Eds.), Advances in social cognition: a dual process model of impression formation ,1-36.

Campion, M. A., Medsker, G. J., \& Higgs, A. C. (1993). Relations between work group characteristics and effectiveness: Implications for designing effective work groups. Personnel Psychology, 46, 823-850. http://dx.doi.org/10.1111/j.1744-6570.1993.tb01571.x

Campion, M. A., Papper, E. M., \& Medsker, G. J. (1996). Relationship between work team characteristics and effectiveness: A replication and extension. Personnel Psychology, 49, 429-452. http://dx.doi.org/10.1111/j.1744-6570.1996.tb01806.x

Cohen, S. G., Ledford, Jr., G. E., \& Spreitzer, G. M. (1996). A predictive model of self-managing work team effectiveness. Human Relations, 49, 643-676. http://dx.doi.org/10.1177/001872679604900506

Combs,M,G., Luthans,F. (2007). Diversity Training: Analysis of the Impact of Self-Efficacy. Human Resource Development Quarterly 18:1 (Spring 2007), pp. 91-120; doi 10.1002/hrdq.1193 Copyright (C) 2007 Wiley Periodicals, Inc. Used by permission. http://www.interscience.wiley.com

DeDreu, C. K. W., \& Van Vianen, A. E. M. (2001). Managing relationship conflict and the effectiveness of organizational teams. Journal of Organizational Behavior,22, 309-328. http://dx.doi.org/10.1002/job.71

Fiske, S. T., Cuddy, A. J. C., Glick, P., Xu, J. (2002). A model of (often mixed) stereotype content: Competence and warmth respectively follow from perceived status and competition.Journal of Personality and Social Psychology, 82 (6), 878-902 http://dx.doi.org/10.1037/0022-3514.82.6.878

Guzzo, R. \& Dickson, M. (1996). Teams in organizations: Recent research on performance and effectiveness. Annual Review of Psychology, 47, 307-338. http://dx.doi.org/10.1146/annurev.psych.47.1.307

Hackman, J. R. (1987). The design of work teams. In J. Lorsch (Ed.), Handbook of organizational behavior, $315-342$. Englewood Cliffs, NJ: Prentice-Hall.

Hackman, J. R. (1992). Group influences on individuals in organizations. In M. D. Dunnette \& L. M. Hough (Eds.), Handbook of industrial and organizational psychology , 3, 199-267. Palo Alto, CA: Consulting Psychologists

Hambrick, D. C., \& Mason, P. A. (1984). Upper Echelons: the Organization as a Reflection of its Top Managers. Academy of Management Review, 9, 193-206.

Hoffman, L. R., \& Maier, N. R. F. (1961). Quality and Acceptance of Problem Solutions by Members of Homogeneous and Hetero-geneous Groups. Joumal of Abnormal and Social Psychology, 62, 401-407. http://dx.doi.org/10.1037/h0044025

Jehn, K. A., Northcraft, G.B., \& Neale, M. A. (1999). Why differences make a difference: A field study of diversity, conflict, and performance in workgroups. Administrative Science Quarterly, 44, 741-763. http://dx.doi.org/10.2307/2667054

Joshi, A., \&Roh, H. (2009). Context In Team Diversity Research: A Meta-Analytic Review. Acadmey of Management Journal, 52(3), 599-627. http://dx.doi.org/10.5465/AMJ.2009.41331491

Larkey, L .K. (1996). Towards a Theory of Communicative Interactions in Culturally Diverse Workgroups, Academy of Management Review, 1996 - jstor.org ... 21, No. 2, 463-491. 
Lovelace, K., Shapiro, D. L., \& Weingart, L. R. (2001). Maximizing cross-functional new product teams' innovation and constraint adherence: A conflict communications perspective. Academy of Management Journal, 44(4), 779-793. http://dx.doi.org/10.2307/3069415

LePine, J. A., Hollenbeck, J. R., Ilgen, D. R., \& Hedlund, J. (1997). Effects of individual differences on the performance of hierarchical decision-making teams: Much more than g. Journal of Applied Psychology, 82, 803-811. http://dx.doi.org/10.1037/0021-9010.82.5.803

McGrath, J. E. (1964). Social psychology: A brief introduction. New York: Holt, Rinehart, and Winston

McGrath, J. E. (1984). Groups: Interaction and performance. Englewood Cliffs, NJ: Prentice Hall.

McGrath, J. E. (1990). Time matters in groups. In J. Galegher, R. Krout, \& C. C. Egido (Eds.), Intellectual teamwork, 23-61. Hillsdale, NJ: Prentice Hall.

McGrath, J. E. (1991). Time interaction, and performance (TIP): A theory of small groups. Small Group Research, 22, 147-174. http://dx.doi.org/10.1177/1046496491222001

Milliken, F., \& Martins, L. (1996). Searching for common threads: Understanding the multiple effects of diversity in organizational groups. Academy of Management Review, 21, 402-433. OECD (2006)

O'reily, C. A., Caldwell, D. F., \& Barnett, W. P. (1989). Work group demography, social integration, and turnover. Administrative Science Quarterly, 34, 21-37. http://dx.doi.org/10.2307/2392984

Pelled, L. H., Eisenhardt, K. M., \& Xin, K. R. (1999). Exploring the black box: An analysis of work group diversity, conflict, and performance. Administrative Science Quarterly, 44, 1-28. http://dx.doi.org/10.2307/2667029

Quinn, A., \& Finkelstein (1996). Managing professional intellect: A review of the approach, The Open Polytechnic of New Zealand 2001

Reagans, R., \& Zuckerman, E. W. (2001). Networks, diversity, and productivity: The social capital of corporate R\&D teams. Organization Science, 12, 502-517. http://dx.doi.org/10.1287/orsc.12.4.502.10637

Richard, O., McMillan, A., Chadwick, K., \& Dwyer, S. (2003). Employing an innovation strategy in racially diverse workforces: Effects on firm performance. Group and Organization Management, 28: 107-126. http://dx.doi.org/10.1177/1059601102250022

Reskin, B. F., McBrier, D. B., \& Kmec, J. A. (1999). The Determinants and Consequences of Workplace Sex and Race Composition. Annual Review of Sociology 25; 335-361. http://dx.doi.org/10.1146/annurev.soc.25.1.335

Riordan, C., \& Shore, L. (1997). Demographic diversity and employee attitudes: Examination of relational demography within work units. Journal of Applied Psychology, 82, 342-358. http://dx.doi.org/10.1037/0021-9010.82.3.342

Schippers, M. C., Hartog, D. N., Koopman, P. L., \& Wienk, J. A. (2003). Diversity and team outcomes: The moderating effects of outcome interdependence and group longevity and the mediating effect of reflexivity. Journal of Organizational Behavior, 24, 779-802. http://dx.doi.org/10.1002/job.220

Simons, T., Pelled, L. H., \& Smith, K. A. (1999). Making use of difference: Diversity, debate, and decision comprehensiveness in top management teams. Academy of Management Journal, 42, 662-673. http://dx.doi.org/10.2307/256987

Triandis, H.C., Kurowski, L. L., \& Gelfand, M. J. (1994). Workplace diversity. In H.C. Triandis, M. P. Dunnette, \& L. M. Hough (Eds.), Handbook of Industrial and Organizational Psychology (2 ${ }^{\text {nd }}$ ed., 4, 769-827). Palo Alto, CA: Consulting Psychologists Press.

Tsui, A.S., Egan, T.D., \& O'Reilly, C.A. (1992). Being different: Relational demography and organizational attachment. Administrative Science Quarterly, 37, 549-579. http://dx.doi.org/10.2307/2393472

Turner, J.C., Hogg, M.A., Oakes, P.J., Rieicher, S.D., \& Wetherell, M.S. (1987). Rediscovering the social group: A self-categorization theory. Oxford, United Kingdom: Blackwell.

Van Knippenberg, D., De Dreu, C., \& Homan, A.C. (2004). Work Group Diversity and Group Performance: an Integrative Model and Research Agenda. Journal of Applied Psychology, 89(6), 1008-1022. http://dx.doi.org/10.1037/0021-9010.89.6.1008

Watson, W. E., Johnson, L., \& Merritt, D. (1998). Team orientation, self-orientation, and diversity in task groups. Group \& Orginzation Studies, 23, Issue 2, pp. 161-188atson, 
Wiersema, M. F., \& Bantel, K. A. (1992). Top Management Team Demography and Corporate Strategic Change. Academy of Management Journal, 35, 95-121.

Williams, K.Y., \& O'Reilly, C.A. (1998). Demography and diversity in organizations A review of 40 years of research. Research in Organizational Behavior, 20, 77-140.

Zenger, T. R., \& Lawrence, B. R. (1989), Organizational Demography: The Differential Effects of Age and Tenure Distributions on Technical Communication. Academy of Management Journal, 32, 353-376. http://dx.doi.org/10.2307/256366

Table 1. The Response Rate for the Four Banks

\begin{tabular}{|c|c|c|c|c|c|}
\hline & SCB(Pakistan) & MCB & Citi Bank & Deutsche Bank & Total \\
\hline Target sample size & 25 & 25 & 25 & 25 & 100 \\
\hline Actual Sample size & 24 & 20 & 20 & 22 & 86 \\
\hline Response rate & $96 \%$ & $80 \%$ & $80 \%$ & $88 \%$ & $86 \%$ \\
\hline
\end{tabular}

Table 2. Type of Diversity

\begin{tabular}{|c|c|}
\hline Type of Diversity & $\%$ \\
\hline Age & 80 \\
\hline Gender & 49 \\
\hline Ethnic & 15 \\
\hline Education & 73 \\
\hline Function & 77 \\
\hline Org.Tenure & 62 \\
\hline Any Other: Position in org. & 60 \\
\hline
\end{tabular}

* Percentages do not add up to 100 because of multiple responses

Table 3. Impact of Relations Oriented Diversity in service industry

\begin{tabular}{|c|c|c|}
\hline Relation Oriented Diversity & Mean Score Values & *Standard Deviation \\
\hline Age & 3.1 & 0.41 \\
\hline Gender & 3.3 & 0.74 \\
\hline Ethnic & 3.1 & 0.72 \\
\hline Relation Oriented Combined Values $(\mathrm{n}=86)$ & $\mathrm{X} 1=3.16$ & $\mathrm{~S} 1=0.62$ \\
\hline
\end{tabular}

*Calculations from frequency table in appendix 3

Table 4. Impact of Task Oriented Diversity on team performance in Service Industry

\begin{tabular}{|c|c|}
\hline Task Oriented Diversity & Mean Score Values \\
\hline Function & 3.0 \\
\hline Education & 3.2 \\
\hline Organizational Tenure & 3.1 \\
\hline
\end{tabular}

Table 5. Impact of Relations Oriented Diversity in Majority Dominant Teams

\begin{tabular}{|c|c|c|}
\hline Variables & Mean Scores & St.Deviation \\
\hline Age & 2.4 & 1.02 \\
\hline Gender & 1.9 & 0.59 \\
\hline Ethnic & 1.9 & 0.72 \\
\hline Combined value & 2.06 & 0.78 \\
\hline
\end{tabular}


Table 6. Impact of Task Oriented Diversity in Majority Dominant Teams

\begin{tabular}{|c|c|c|}
\hline variables & Mean Score & St.Deviation \\
\hline Function & 3.2 & 0.68 \\
\hline Education & 3.2 & 0.71 \\
\hline Tenure & 3.2 & 0.56 \\
\hline Combined Values & 3.2 & 0.65 \\
\hline
\end{tabular}

Table 7. Impact of Relations Oriented Diversity in Balanced Teams

\begin{tabular}{|c|c|c|}
\hline Variables & Mean Score & St.Deviation \\
\hline Age & 3 & 0.68 \\
\hline Gender & 3.8 & 0.57 \\
\hline Ethnic & 3.8 & 0.52 \\
\hline Combined value & 3.53 & 0.61 \\
\hline
\end{tabular}

Table 8. Impact of Task Oriented Diversity in Balanced Teams

\begin{tabular}{|c|c|c|}
\hline Variables & Mean Score & St.Deviation \\
\hline Function & 3.2 & 0.82 \\
\hline Education & 3.2 & 0.63 \\
\hline Tenure & 3.2 & 0.48 \\
\hline Combined Values & 3.2 & 0.643 \\
\hline
\end{tabular}

Table 9. Relations Diversity and Short Term Teams

\begin{tabular}{|c|c|c|}
\hline Variables & Mean Score & St.Deviation \\
\hline Age & 3.1 & 0.73 \\
\hline Gender & 3.3 & 0.56 \\
\hline Ethnic & 3.3 & 0.57 \\
\hline Combined value & 3.23 & 0.62 \\
\hline
\end{tabular}

Table 10. Task Oriented Diversity and Short term teams

\begin{tabular}{|c|c|c|}
\hline Variables & Mean Score & St.Deviation \\
\hline Function & & 0.82 \\
\hline Education & 3.2 & 0.63 \\
\hline Tenure & 3.2 & 0.48 \\
\hline Combined Values & 3.2 & 0.643 \\
\hline
\end{tabular}

Table 11. Relation Oriented Diversity and Long TermTeams

\begin{tabular}{|c|c|c|}
\hline Variables & Mean Score & St.Deviation \\
\hline Age & 2.7 & 0.54 \\
\hline Gender & 2.5 & 0.78 \\
\hline Ethnic & 2.7 & 0.8 \\
\hline Combined value & 2.63 & 0.71 \\
\hline
\end{tabular}

Table 12. Task Oriented Diversity and Long term teams

\begin{tabular}{|c|c|c|}
\hline Variables & Mean Score & St.Deviation \\
\hline Function & 3.1 & 0.08 \\
\hline Education & 3.3 & 0.63 \\
\hline Tenure & 3.1 & 0.52 \\
\hline Combined Values & 3.16 & 0.41 \\
\hline
\end{tabular}




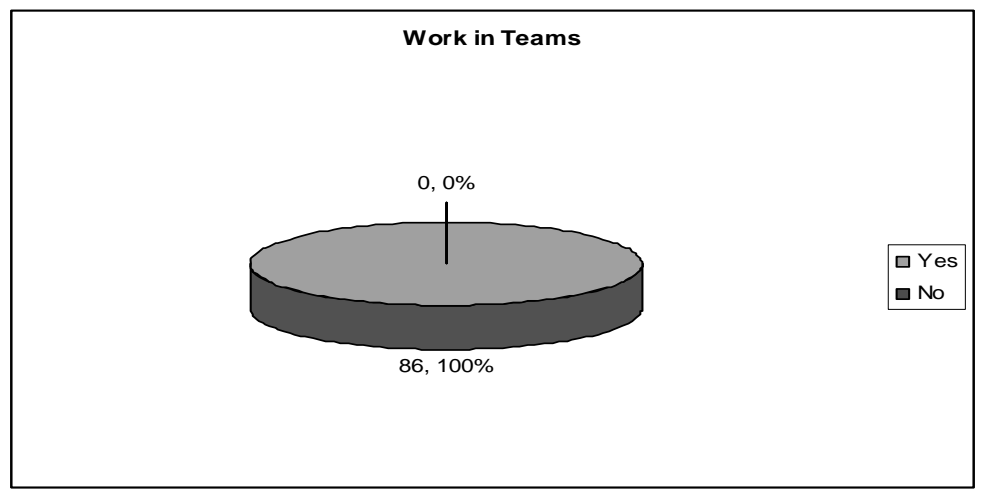

Figure 1. Practice of Teamwork

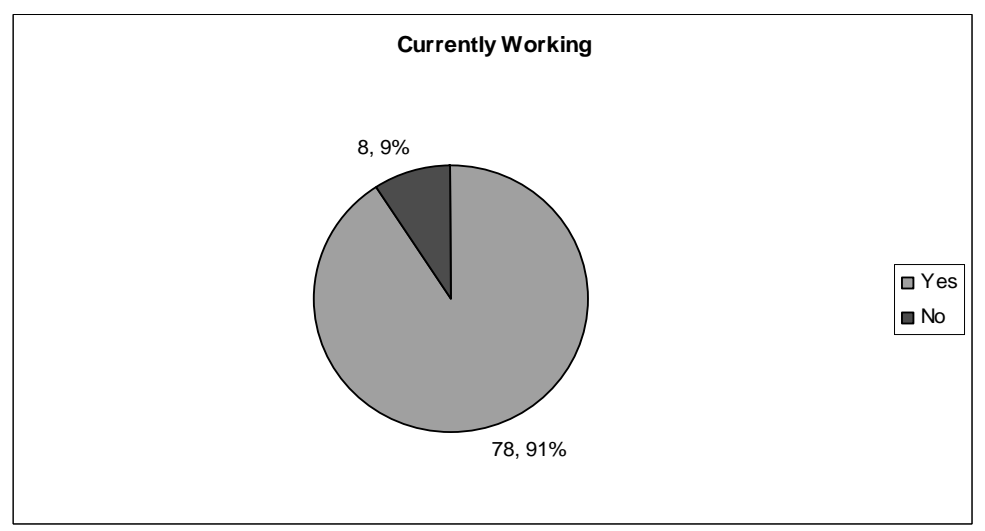

Figure 2. Currently working in teams

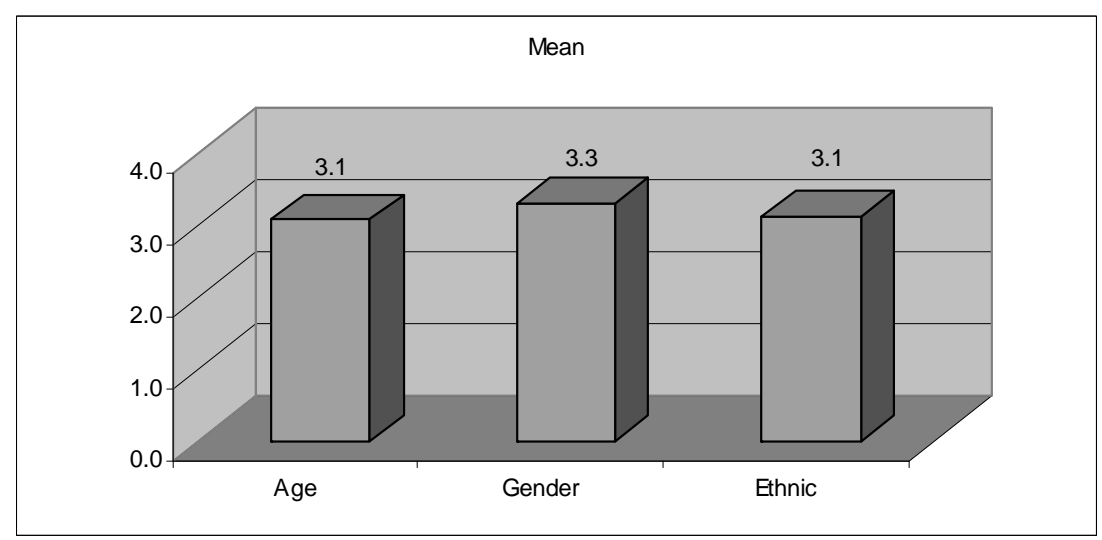

Figure 3. Impact of Relations Oriented Diversity on team performance in service industry 


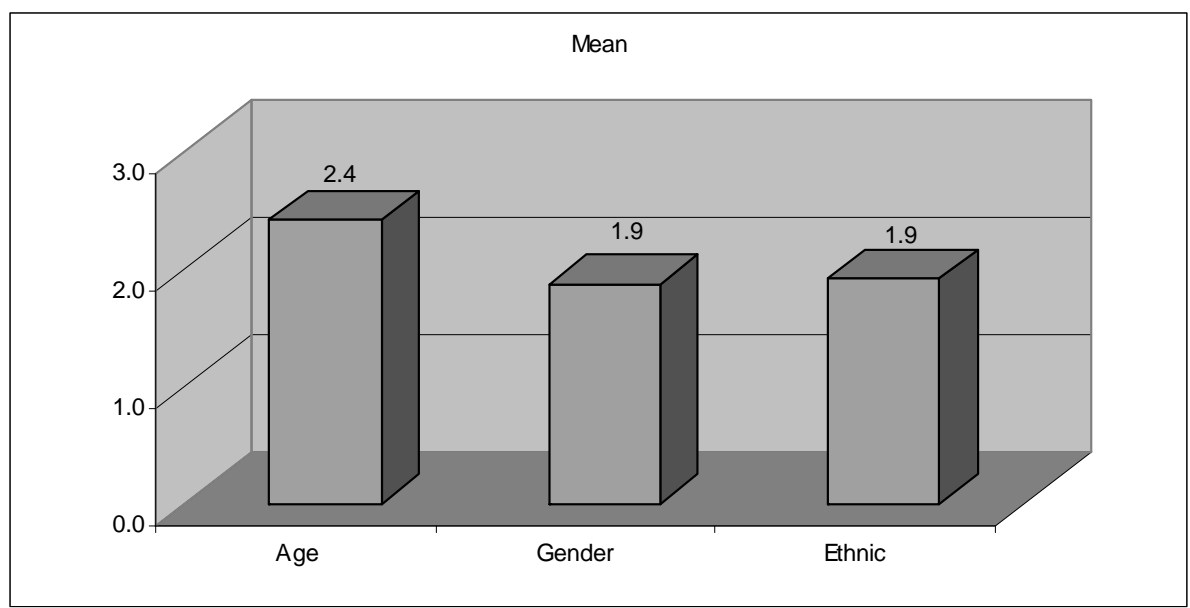

Figure 4

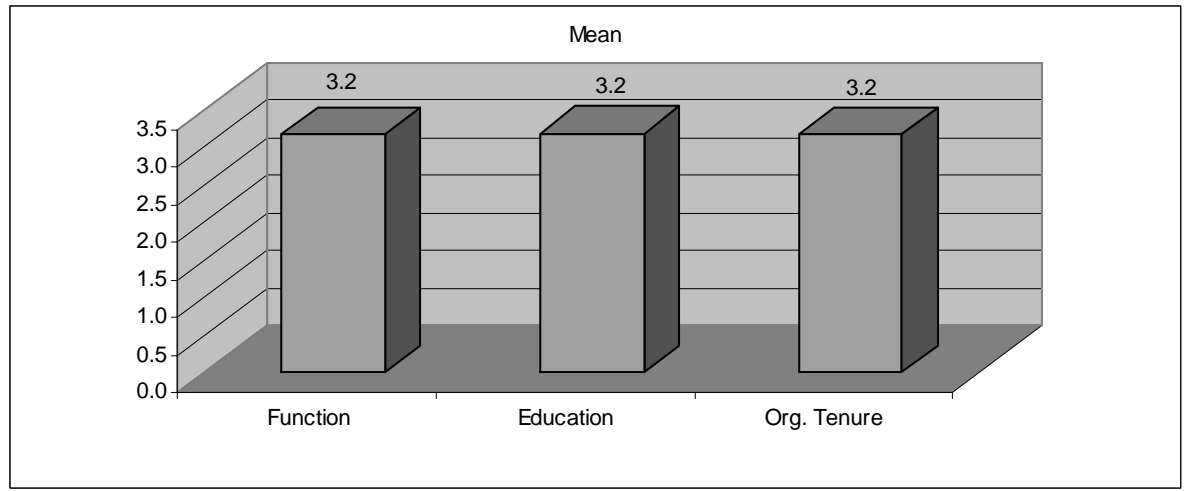

Figure 5

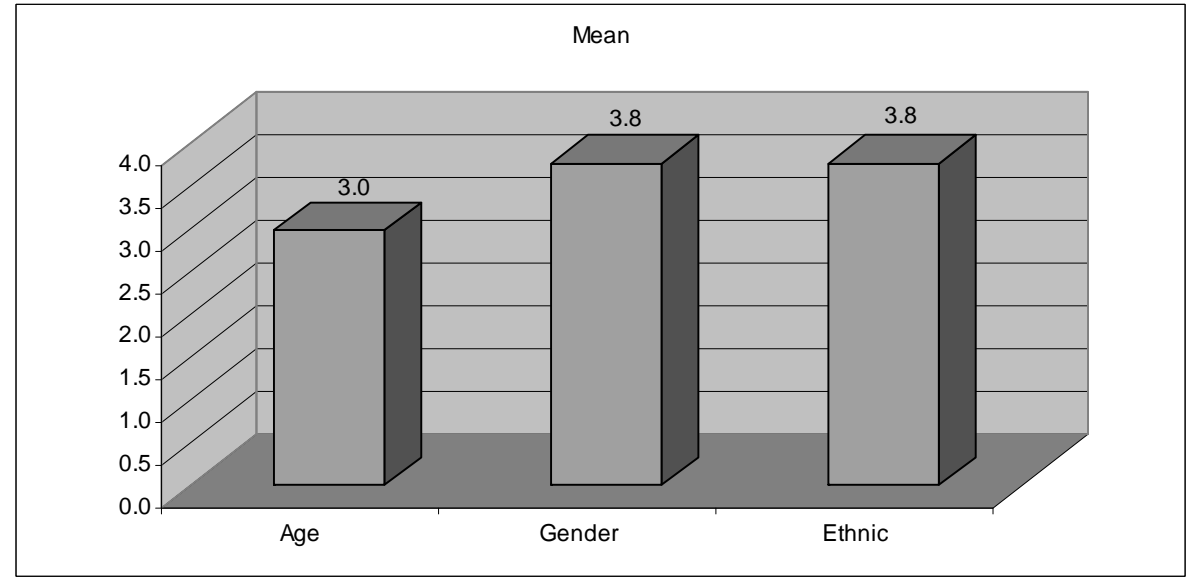

Figure 6 


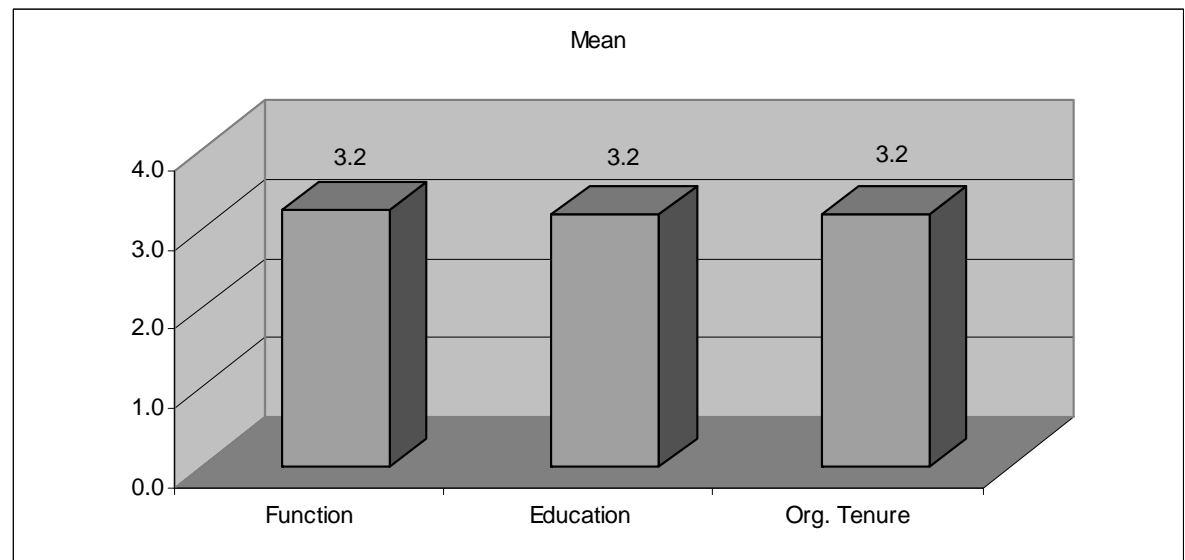

Figure 7

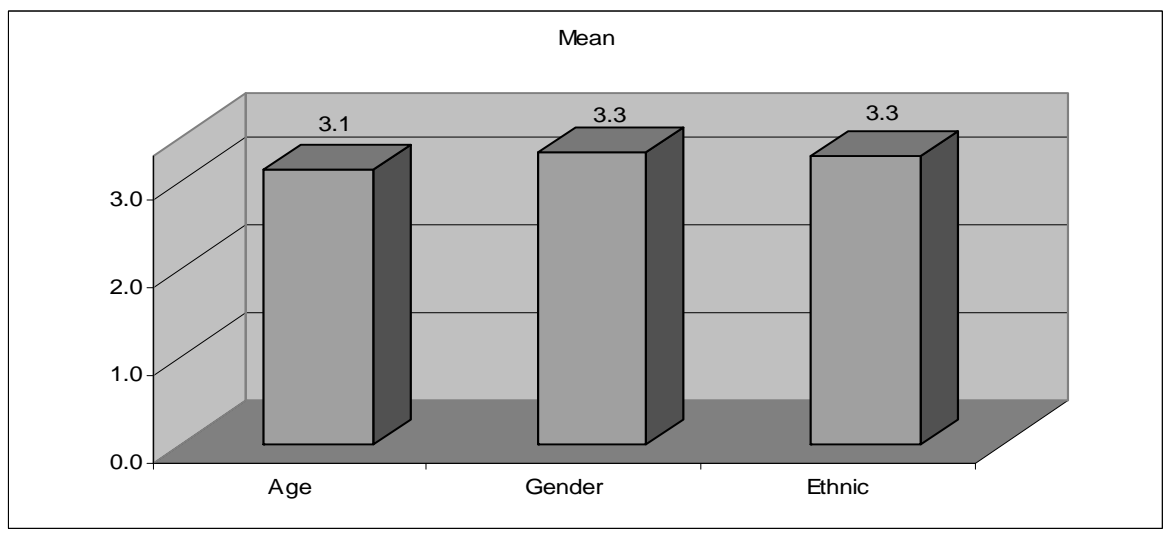

Figure 8

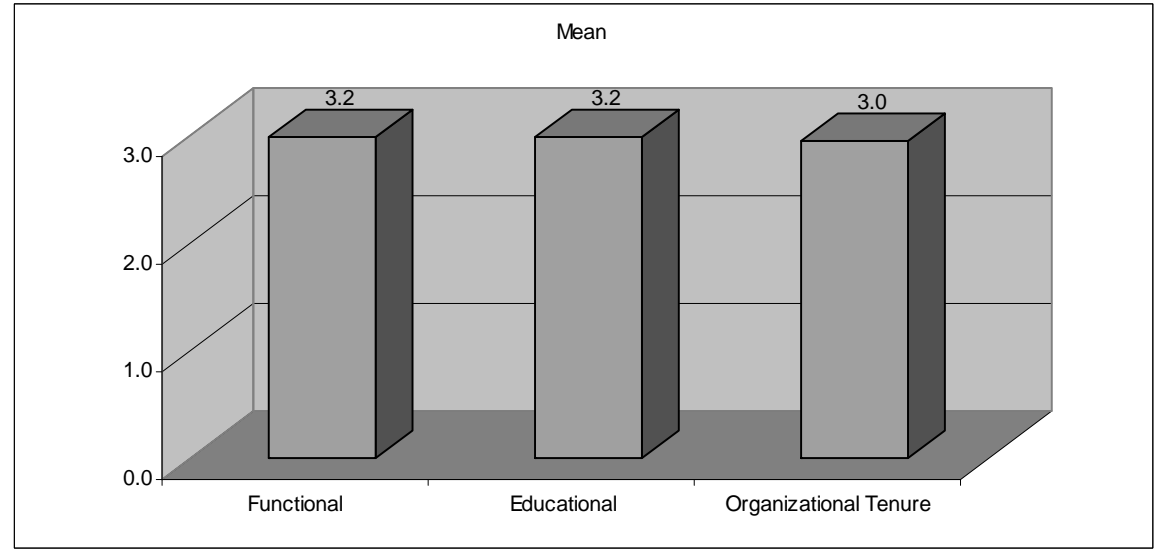

Figure 9 


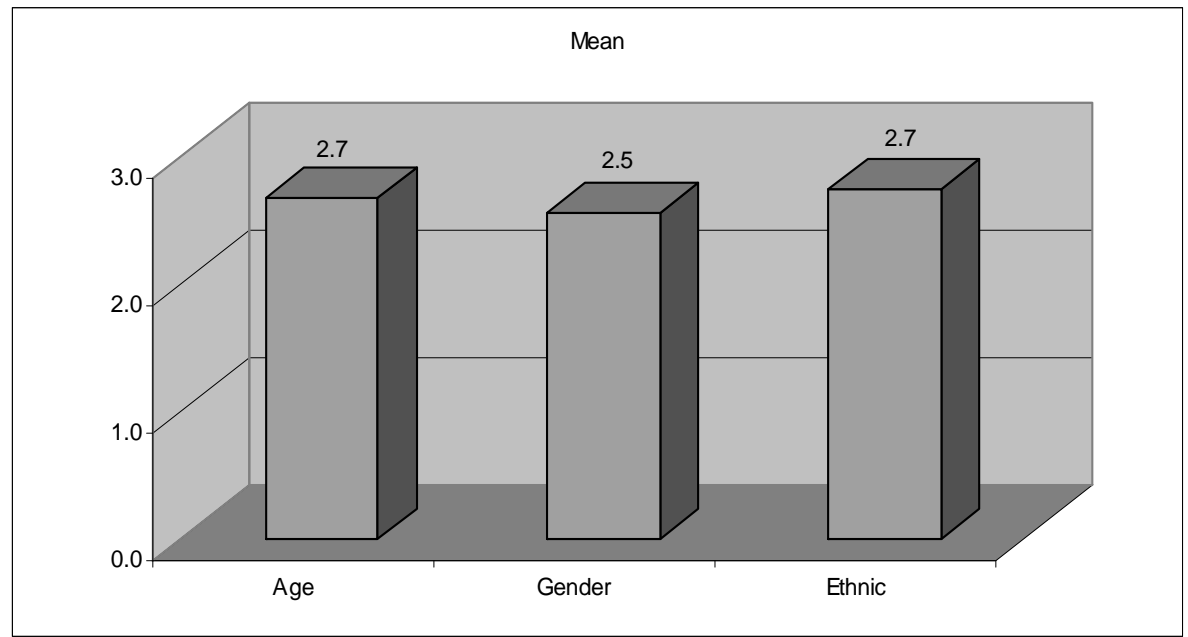

Figure 10

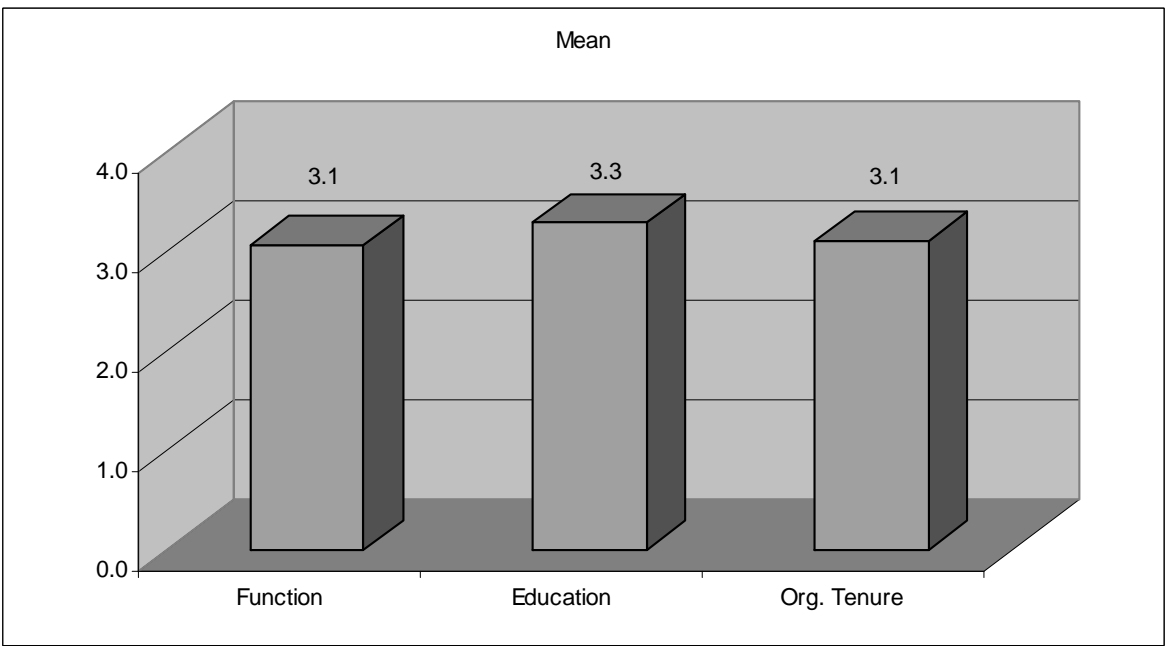

Figure 11 